\title{
Numerical, Mechanical, and Metallurgical Investigation of an Innovative Near Net Shape Titanium Selective Laser Melting Engine Component and Comparison with the Conventional Forged One
}

\author{
Silvia Cecchel,* Davide Ferrario, Francesco Mega, and Giovanna Cornacchia
}

Selective laser melting (SLM) can be used to manufacture near net shape (NNS); the main benefits are a remarkable weight reduction, a lower environmental impact, the opportunity to integrate some functions, and an improvement of the performances. The current article covers the development of a Ti6Al4V NNS engine component produced by SLM. Finite element analyses of the main relevant operating conditions are performed to reach a topological optimization of the part. The main target is weight reduction keeping the same safety performances. The weight reduction achieved is $45 \%$ and $15 \%$ with respect to steel and titanium forging by replacing the original " $\mathrm{H}$ " section with an SLM multibranch structure. Other benefits are the manufacturing of the connecting rod (conrod) into two separate parts, avoiding the difficult machining to separate the cap from the main body and the integration of conformed cooling channels into the conrod. Then, the SLM components are produced and mechanical and metallurgical properties are investigated and compared with the titanium hot forging ones. Both the macrostructures present equiassic and isotropic behavior due to the heat treatment transformation. No defects are observed for both the technologies. The mechanical properties are verified to be aligned with the design targets.

\section{Introduction}

As is well known today, additive manufacturing (AM) is a process of joining materials to make objects from 3D model data as opposed to subtractive manufacturing methodologies which remove material. ${ }^{[1]}$ In general, AM technology allows the manufacturing of parts directly from digital model by depositing the material through a layer-by-layer approach that is digitally controlled. This emerging technology can manufacture metallic

Dr. S. Cecchel, Dr. D. Ferrario, Dr. F. Mega

Research and Development

Streparava SpA

Via Zocco 13, Adro, BS 25030, Italy

E-mail: s.cecchel@streparava.com

Dr. G. Cornacchia

Department of Mechanical and Industrial Engineering

University of Brescia

via Branze 38, Brescia 25123, Italy

The ORCID identification number(s) for the author(s) of this article can be found under https://doi.org/10.1002/adem.202100036.

DOI: 10.1002/adem.202100036 components with high precision. Among the main advantages, it can be found freedom of part design, part complexity, lightweighting, part consolidation, and design for specific functions. In light of this, AM technologies could provide an optimal trade-off between the need to increase manufacturing speed for highly customized and complex parts while achieving required mechanical properties with near net shaped components containing fewer defects. All these aspects are of interests in metal AM for aerospace, oil and gas, marine, and transport applications. ${ }^{[2]}$

Among these processes, particularly selective laser melting (SLM) is one of the most used. This is a powder bed fusion process that uses metal powder, mainly for the manufacturing of components belonging to the biomedical and automotive field. ${ }^{[3-5]}$ SLM has the great benefit to generate very complex shapes ${ }^{[6]}$ that are often impossible to be produced with the conventional technologies. Thus, near net shape (NNS) parts and undercuts can be now easily created with this new technology. Another SLM benefit could be the creation of internal passages by maintaining a good dimensional control; this could be used, for example, for the integration of cooling channels. A first benefit that can be gathered is the reduction of metalworking operation. In the automotive field, the opportunity to create lightweight components ${ }^{[7-9]}$ due to a NNS design is even more important. Indeed, this is one of the most feasible measures to reduce the vehicle emissions ${ }^{[10-12]}$ and consequently the traffic-related air pollution. As mentioned earlier, it is clearly the need to modify how engineers think when designing parts; the typical design of traditional subtractive manufacturing processes is very different from the new shapes achievable with $A M .^{[13]}$ Thus, to take full advantage of unique capabilities from AM processes, specific Design for Additive Manufacturing (DfAM) methods are needed. Typical DfAM includes topology optimization and other design methods which can be supported by AM-enabled features. In the automotive domain, SLM is currently limited for the production of prototypes or rare spare parts, while research is moving toward a larger adoption of this technology, ${ }^{[14,15]}$ for example, targeting the production of components for high-end and luxury vehicles. 
In this context, the present research work studied the topological optimization of a challenging engine part, a connecting rod (conrod). SLM was analyzed in substitution of one of the conventional manufacturing (CM) most used, the forging. To the best of the authors' knowledge, it is worthwhile to note that the current literature offers very few case studies in which AM and the original CM products are compared and there are not any other applications with the particular geometry achieved during this investigation.

For better understanding the current research work, it is important to introduce some general notions.

The function of the conrod is to transmit the force of the engine piston to the crankshaft and to convert the transverse motion of the former into rotation of the latter. Consequently, it has to ensure the necessary mechanical resistance under loading, and it has to be as light as possible to reduce the inertia forces. ${ }^{[16]}$ The material mainly used is steel, but during the last decades titanium has been applied for lightweighted applications $^{[16-19]}$ in niche markets (i.e., motorsport Honda NSX (1989), Honda RC30 (1990), Corvette Z06 (2006), Yamaha YZF-R1M (2014), Yamaha YZF-R1M (2014), and Porsche 911 GT3 (2014)). Indeed, the applications just mentioned are very sensible to weight reduction of engine parts because, in addition to a reduction of environmental impact, this measure brings also a performance increasing. Thus, these niche applications could be suitable to implement a further and extreme weight reduction, such that reachable through the SLM NNS design. Furthermore, the typical volume of production in these fields is low in comparison with the general automotive market and the component dimensions are limited that makes the application suitable for the AM technology capabilities.

From a process point of view, hot forging is the predominant $\mathrm{CM}$ to fabricate titanium conrods. ${ }^{[16,18]}$ After forging, trimming is performed in a separate die and successively the component is heat treated. An issue for the forged titanium conrod consists in its difficult machining, ${ }^{[20]}$ in particular related to the operation of cutting into two parts the big eye (cap and main body) to allow the connection with the crankshaft. The typical microstructure of forged $\mathrm{Ti}_{6} \mathrm{Al}_{4} \mathrm{~V}$ after annealing is composed of equiaxed $\alpha$ grains and lamellar $\alpha+\beta .^{[21]}$ Average mechanical properties required for this application are $\sigma_{\mathrm{y}}=880, \sigma_{\mathrm{m}}=950, A \%=11 \%$.

On the contrary, in general SLM process consists of localized and high heat inputs that lead to a different microstructure (fine acicular $\alpha^{\prime}$ martensite) than $\mathrm{CM}^{[22]}$ and cause residual stress development. ${ }^{[5]}$ To answer this issue, specific heat treatments are required for Ti6Al4V made by SLM to properly modify the components microstructure and to reduce as much as possible the residual stresses. Different researchers studied on samples the main relevant heat treatment classes: 1) annealing $\left(700^{\circ} \mathrm{C}<\mathrm{T}<800^{\circ} \mathrm{C}\right)$ and 2) solubilization super- $\beta$ transus $\left(T>980^{\circ} \mathrm{C}\right)$ or 3$)$ sub- $\beta$ transus $\left(T<980^{\circ} \mathrm{C}\right)$ followed by a tempering between 700 and $950^{\circ} \mathrm{C}$. For example, Vilaro et al. ${ }^{[23]}$ analyzed the microstructure and mechanical properties after different heat treatments; Vracken et al. ${ }^{[21]}$ focused mainly on the influence of time, temperature, and cooling rate of the heat treatments by means of microstructural investigation and tensile tests in comparison with CM; and Simonelli et al. ${ }^{[4]}$ and Longhitano et al. ${ }^{[23]}$ analyzed different temperatures for the stress reliving. From these studies it can be gathered that the $\alpha^{\prime}$ phase of the as-built condition is transformed into a mixture of $\alpha+\beta$ phases after annealing and $\alpha+\beta$ phases with $\alpha$-Widmanstatten or $\alpha^{\prime}$ martensite or $\alpha^{\prime \prime}$ new martensite, depending on time, temperature, and cooling rate, after annealing solubilization and tempering.

From the analysis of the aforementioned literature and after a previous research work on samples produced in the same batch of the conrod, ${ }^{[25]}$ the following heat treatment was considered the best option to achieve the desired mechanical properties on the SLM conrods: super- $\beta$ transus solubilization followed by a tempering. Indeed, considering the specific application, this heat treatment shows the best match of mechanical properties, residual stresses, and corrosion resistance.

The current article started from the topological optimization of the new SLM conrod. Then, microstructures and mechanical resistance of CM and SLM actual conrod parts (shown in Figure 1) were analyzed and compared.

The main benefits achieved through the new SLM option are weight reduction (45\% and 15\% with respect to steel and titanium forging, respectively), manufacturing of the conrod into two separate parts that avoid the difficult machining to separate the cap from the main body, and the integration of conformed cooling channels into the conrod.

\section{Experimental Section}

\subsection{Topological Optimization}

The topology optimizations were conducted through Altair Optistruct software starting from the 3D model of the CM forging conrod. The average dimensions of the component are $178 \times 24 \times 75 \mathrm{~mm}^{3}$.

The finite element models used for both geometries are composed of primarily tetrahedron elements. The finite element model is composed of about 55047 degrees of freedom, 52376 elements, and 15902 nodes. All the analyses were performed considering the material in linear elastic field. Several simulations were conducted on gradually improved geometries and their mechanical behavior was analyzed until the best configuration was reached.
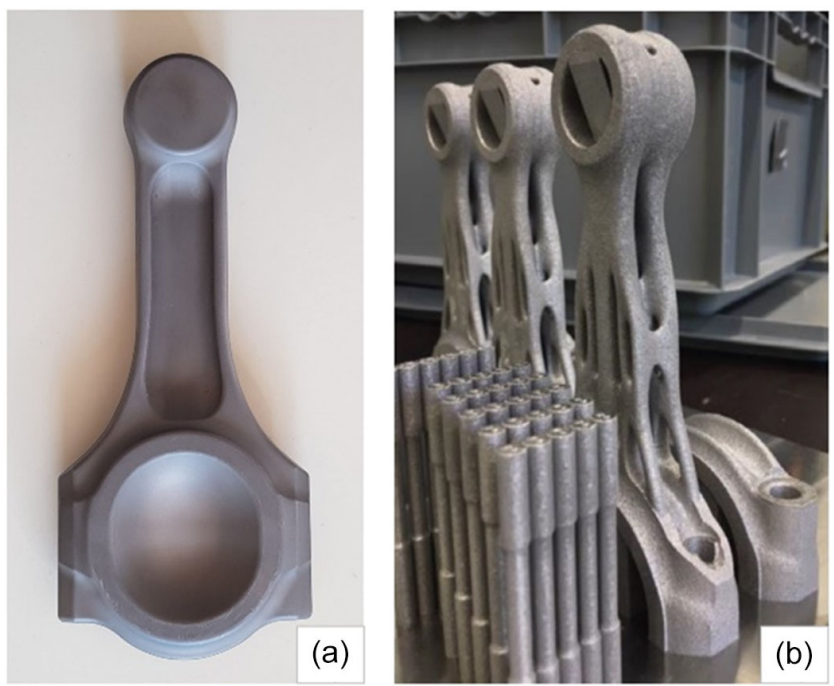

Figure 1. a) $\mathrm{Ti}_{6} \mathrm{Al}_{4} \mathrm{~V}$ hot forged and b) SLM conrods. 
The entire system is composed by the conrod and the elements directly connected to this part (crankshaft and engine piston) and can be represented by the well-known cranks and conrod mechanism. This is a mechanical system composed of a rotating element (crank) and a sliding element (piston), connected with a rod (in this case the conrod) allowing the linear sliding motion to be converted into a circular motion.

The modeling methodology for kinematics of the system mechanism has been derived systematically by considering the geometric configuration, speed, and acceleration of the internal combustion engine crank mechanism. ${ }^{[26,27]}$ As specifically regards the conrod kinematic properties, it should be mentioned that a coordinate system integral to the conrod itself was considered. Real data for conrod length, rotational speed of engine, piston mass, and so on were used; maximum acceleration values are related with maximum rotational speed of the crankshaft. To guarantee a high accuracy, the acceleration was considered as a field variable along the conrod (see Figure 2 blue area; $a_{1 \mathrm{~b}}-a_{1 \mathrm{c}}$ for load case 1 and $0-a_{2}$ for load case 2 ). Indeed, axial ( $x$ direction) and transversal ( $y$ direction) accelerations vary with crankshaft angular position and with location along the conrod.

Figure 2 shows a scheme of the three main load cases analyzed for the dimensioning of the mechanical resistance. They are representative of the operating conditions and constitute the necessary requirements to be fulfilled to ensure a reliable application. As regards the load cases, load case 1 (max tension) corresponds to the highest axial acceleration verified when the piston is in the top dead center position and rotational speed is at the maximum level; load case 2 (bending) corresponds to the highest transversal acceleration verified when the crankshaft is perpendicular to the conrod; and load case 3 (max compression) corresponds to the maximum gas loading (also called firing). Thus, $F_{1}$ force is generated from piston group acceleration, while $F_{3}$ from firing. The traditional approach for conrod stress calculation involves the discretization of the mass into few concentrated areas. ${ }^{[28,29]}$ As the target of the study was extreme weight reduction, a higher accuracy was necessary. This is the reason why the acceleration was applied at each mass element with a specific value depending on the position along the conrod. Thus, the acceleration was applied to each finite element during finite element analysis (FEA) optimization. ${ }^{[30]}$ Loops of iterations were conducted to find the most proper configuration in terms of both structural resistance and weight reduction.

The criteria of considered resistance were as follows: 1) $\sigma \leq \sigma_{\text {faf }}$ for the areas with main principal stress $>0$, where $\sigma_{\text {faf }}$ is the material bending fatigue limit having value reported later; 2) $\sigma \leq \sigma_{\mathrm{y}} / \eta$ for the areas with main principal stress $<0$, where $\sigma_{\mathrm{y}}$ is the yield strength having value reported later and $\eta$ is a safety factor $(\eta=2)$.

The material used was a $\mathrm{Ti}_{6} \mathrm{Al}_{4} \mathrm{~V}$ alloy having the following mechanical properties: $\sigma_{\mathrm{y}} 880=\mathrm{MPa}, \sigma_{\mathrm{m}} 950=\mathrm{MPa}, A \%=11 \%$, $\sigma_{\mathrm{faf}}=250 \mathrm{MPa}$, and $E=114 \mathrm{GPa}$ that are the design target for this application.

After the topological optimization, these parts can be SLMed. Additional samples were produced into the same batch of the conrods to properly dimension the postprocess parameters and achieve the design target imposed by the application. A previous research focused on these preliminary investigations ${ }^{[25]}$ aimed at identifying the best heat treatment condition to be replied on the conrods produced with the same SLM process parameters. The details about the production and heat treatments of these components and samples are reported in the following section. The proper achievement of the target mechanical properties due to the heat treatment selected will be checked during the current work. Following this consideration, the FEA on the 3D model of the conrods evaluated by means of target mechanical properties can be considered valid also for the final real application.

\subsection{Samples Description}

Figure 1a shows the hot forged Ti6Al4V conrod studied. The heat treatment condition is annealing. The microstructure was analyzed on specimens cut off from different areas of the conrod, as shown in Figure 3a. Cylindrical samples with a length of $72 \mathrm{~mm}$ and a gauge diameter of $6 \mathrm{~mm}$ were machined out of the component also for tensile tests.

Figure 1b shows the SLM Ti6Al4V conrod produced with the geometry selected at the end of the topological optimization. A super- $\beta$ transus solubilization followed by a tempering heat treatment was performed. As it can be seen, some tensile samples were produced separately from the part because its shape did not allow the extraction directly from the conrod. Cylindrical tensile test samples had a length of $60 \mathrm{~mm}$ and a gauge diameter of $4 \mathrm{~mm}$. Microstructural samples were cut off from both tensile samples and conrods, in the areas shown in Figure 3b.

A minimum of four samples for each condition were analyzed.

\subsection{Microstructural Observation}

The surfaces were prepared with standard metallographic techniques (ground with $\mathrm{SiC}$ papers and polished with $1 \mu \mathrm{m}$

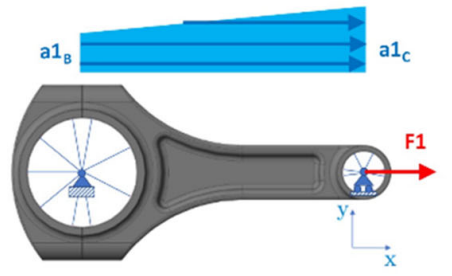

Loadcase 1. Max tension

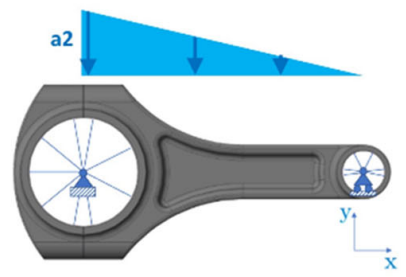

Loadcase 2. Max bending.

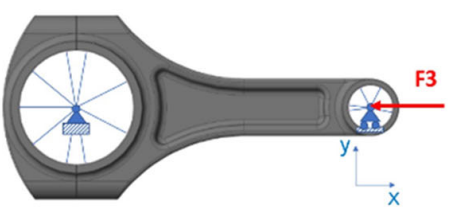

Loadcase 3. Max Compression

Figure 2. Load cases analyzed for the conrod dimensioning. 


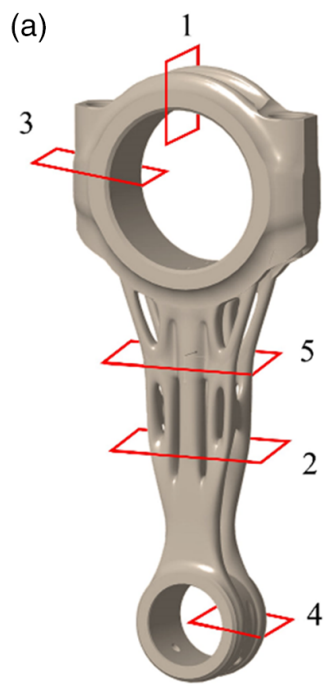

(b)

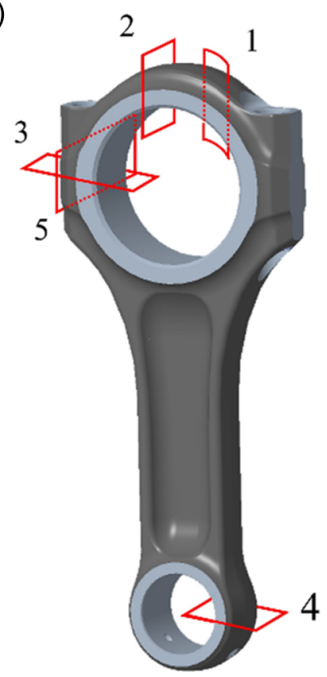

Figure 3. Microstructural samples from a) Ti6Al4V SLM and b) hot forged conrods.

diamond paste) and were etched with a $10 \mathrm{~mL} \mathrm{H}_{2} \mathrm{O}, 5 \mathrm{~mL} \mathrm{HNO}_{3}$, and $1 \mathrm{~mL} \mathrm{HF}$ solution. The microstructure was examined using a Leica DMI 5000M optical microscope and scanning electron microscopy (SEM) LEO EVO 40. Semiquantitative chemical analyses were obtained by means of an energy dispersive spectroscopy (EDS)-Link Analytical eXL probe, with a spatial resolution of a few microns.

\subsection{Hardness and Tensile Test}

Vickers microhardness tests were conducted under $1 \mathrm{kgf}$ load applied for $15 \mathrm{~s}$ on the etched traverse surface, by means of a Mitutoyo HM-200 instrument according to ASTM E92-16. ${ }^{[31]}$

The tensile tests were conducted following UNI EN ISO 6892-1:2009. ${ }^{[32]}$ An electromechanical testing machine Instron 3369 at a strain rate of $1 \mathrm{~mm} \mathrm{~min}^{-1}$ was used.

The SLM tensile cylinder samples analyzed in this research were built directly in this shape to test a condition comparable with the actual component surface. Indeed, it is worthwhile to remember that SLM parts aimed at reducing the weight in automotive are NNS and they have a very low amount of machined surfaces. In addition, the specific thin and complex geometry of the SLM conrods did not allow the machining of tensile samples from the parts. On the contrary, for the forged components, tensile samples machined from its middle beam were used. Their dimensions were already reported in Section 2.2.

\section{Results and Discussion}

\subsection{Topological Optimization, Final Design, and Conrod Manufacturing}

Figure 4 shows the design evolution during the topology optimization starting from the forged design (first image on the left).

As it can be seen, the main constraint is to maintain unchanged the interfaces with the crankshaft ("big end" in

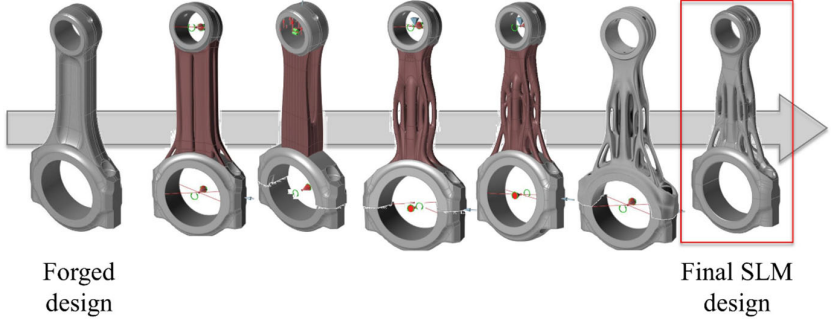

Figure 4. Design evolution from initial hot forged and SLM conrods.

the bottom portion) and with the piston ("small end" in the top portion) when moving from original forged version to new SLM design. Thus, the main relevant changes are in the middle section ("shank") that was gradually modified starting from an " $H$ " section of the forged component up to a multibranch structure of the final SLM design. The target is to reduce the weight as much as possible while maintaining the structural resistance required for the application. The result was a significant weight reduction of about $45 \%$ and $15 \%$ with respect to steel and titanium forging, respectively. This benefit has to be multiplied by four, being the application a four-cylinder engine. Note that the titanium forging application was already optimized to reduce the weight, so the current further lightweight can be considered a very interesting goal. In addition, the SLM conrod was designed to be produced into two separate parts. This is a relevant advantage in terms of manufacturing operations because it deletes the difficult machining to separate the cap from the main body and allow to achieve a NNS component. The reduced amount of machined areas is clear looking at the comparison between forged and SLM raw parts in Figure 1. Finally, the AM conrod was enriched with conformed cooling channels integrated into the branches of its structure that allow a more efficient lubrification than the machined linear channel of the forged version. This beneficial geometry of the channels cannot be obtained with the traditional technology.

Figure 5 and 6 show, respectively, the maximum and minimum stresses resulted from the structural simulations of the three load cases on the final design selected for the SLM conrod manufacturing. As it can be seen, the final design ensures the mechanical resistance required. Indeed, for the maximum principal stresses (Figure 5, criterion for $\sigma>0$ : $\sigma \leq \sigma_{\text {faf }}=250 \mathrm{MPa}$ ) there are not any areas that exceed the limit, while for the minimum principal stress (Figure 6, criterion for $\sigma<0$ : $\sigma \leq \sigma_{\mathrm{y}} /$ $\eta=440 \mathrm{MPa}$ ) only some limited nodes slightly exceed the limit ( $-516 \mathrm{MPa}$ in the maximum compression load case). It is worthwhile to note that these exceptions were verified to correspond to very few local elements and could be related to the mesh dimension. Thus, they were not evaluated to be critical.

\subsection{Microstructural Observation}

Figure 7 shows a representative example of the microstructure of the CM forged samples taken by the conrods. This is a duplex microstructure composed of slightly elongated primary $\alpha$ grains in a matrix of transformed $\beta$ containing $\alpha$ and $\beta$ lamellae. Note that $\alpha$ phase is light while $\beta$ phase is dark. 


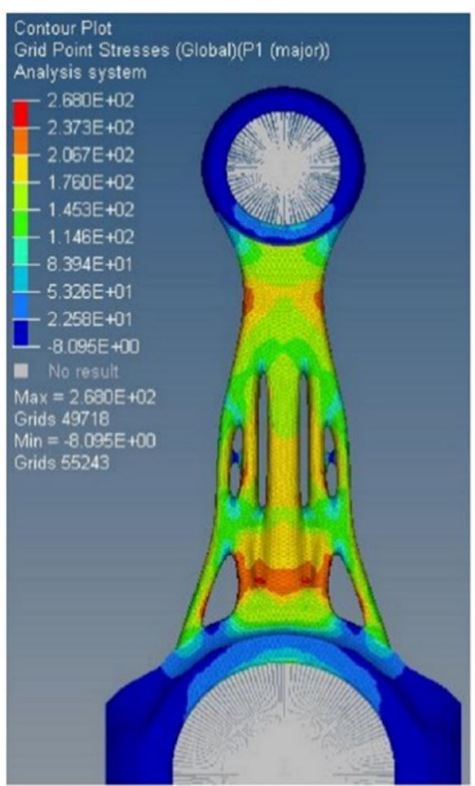

Max tension

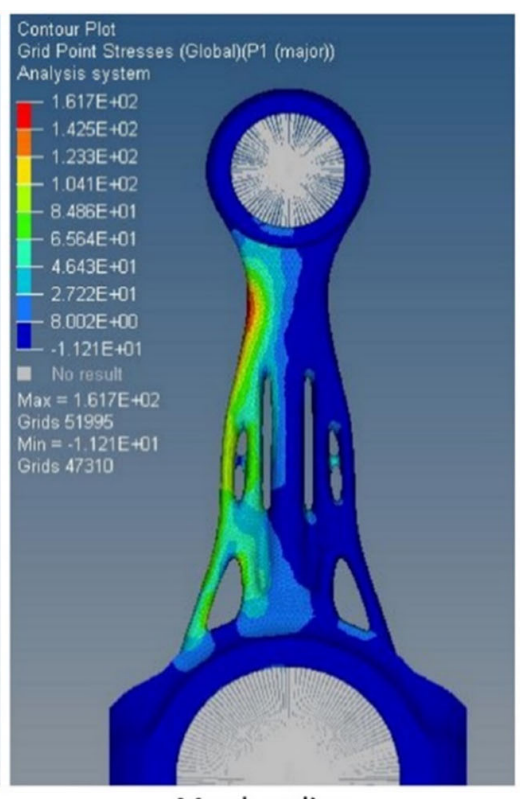

Max bending

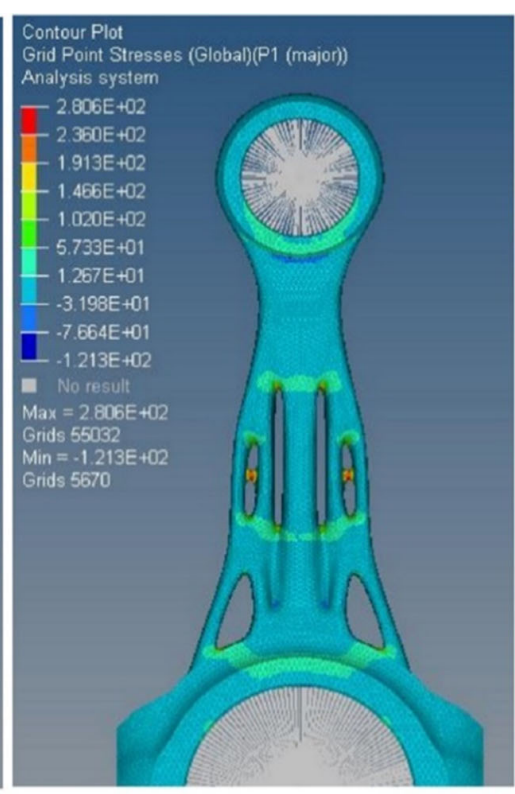

Max compression

Figure 5. Maximum principal stresses of the final SLM conrod design.

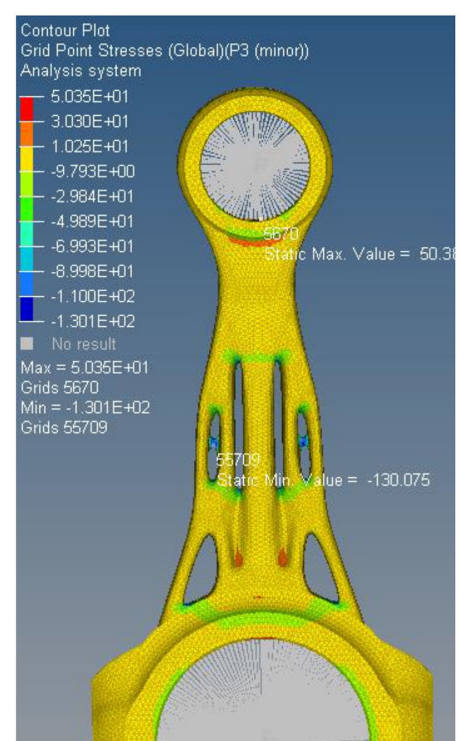

Max tension

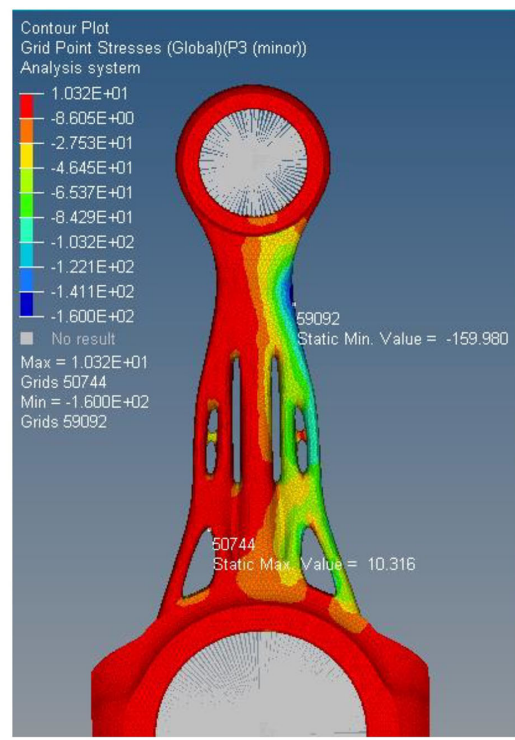

Max bending

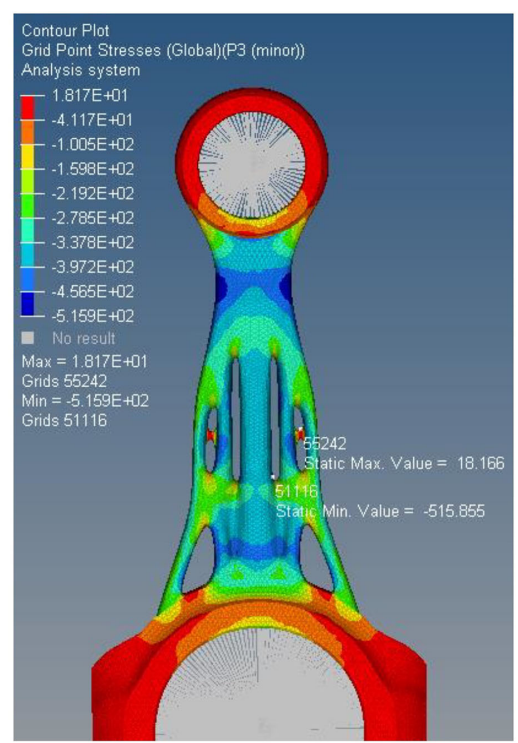

Max compression

Figure 6. Minimum principal stresses of the final SLM conrod design.

Figure 8 shows an example of the microstructure of the samples taken by the SLM conrods. It can be observed the grain boundaries of transformed equiaxial $\beta$ grains with $\alpha$ at prior $\beta$ grain boundaries and containing thin $\alpha$ lamellae. In particular, the isotropy of the macrostructure and the equiaxial grains formation are related to the displacive transformation of the body-centered-cubic phase $(\beta)$ into hexagonal phase $\left(\alpha^{\prime}\right)$ after quenching from super- $\beta$ transus field. For the sake of clarity, Figure 9 shows the macrostructure of $S \mathrm{SM} \mathrm{Ti}_{6} \mathrm{Al}_{4} \mathrm{~V}$ in the transversal $(\mathrm{T})$ and longitudinal (L) sections that further confirm the isotropy of the material. For major details, see the related previous research about this topic. ${ }^{[25]}$

Microstructure at higher magnification was analyzed looking at SEM images, as shown in Figure $\mathbf{1 0}$ and $\mathbf{1 1}$ for forged and SLM section, respectively. For SEM analysis, $\alpha$ phase is dark while $\beta$ phase is light. These investigations, completed by EDS analysis, confirmed the microstructure observed with optical microscope analysis and previously described. Indeed, it can be noted that the lowest amount of vanadium and the highest amount of aluminum are detected in the darkest areas analyzed (spectrum 1 and 2 

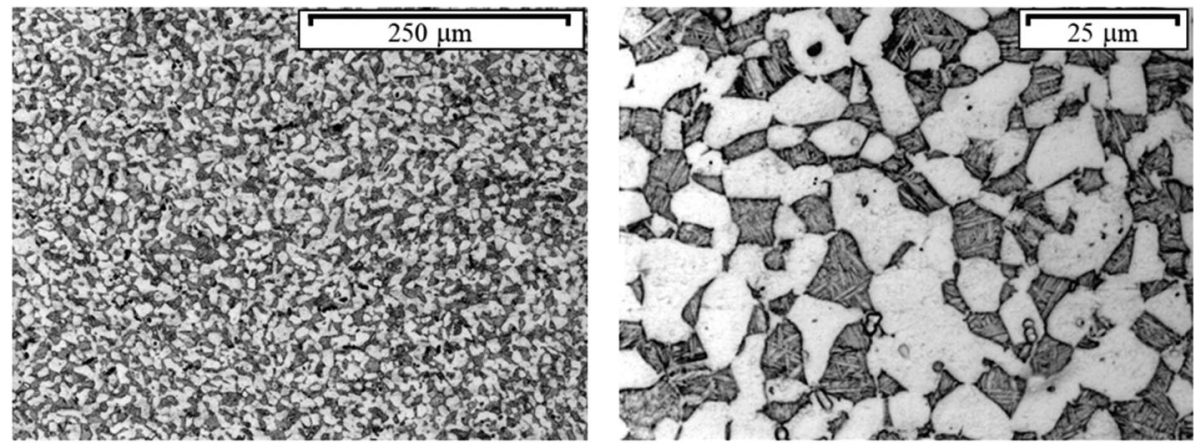

Figure 7. Optical Microstructure of a representative forged Ti6Al4V conrod section.
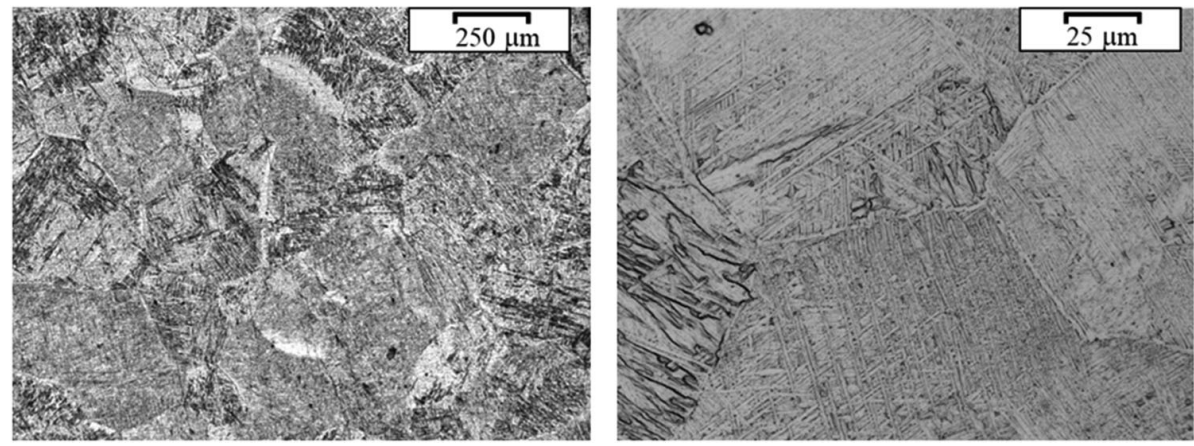

Figure 8. Optical Microstructure of a representative additive manufactured $\mathrm{Ti}_{6} \mathrm{Al}_{4} \mathrm{~V}$ conrod section.
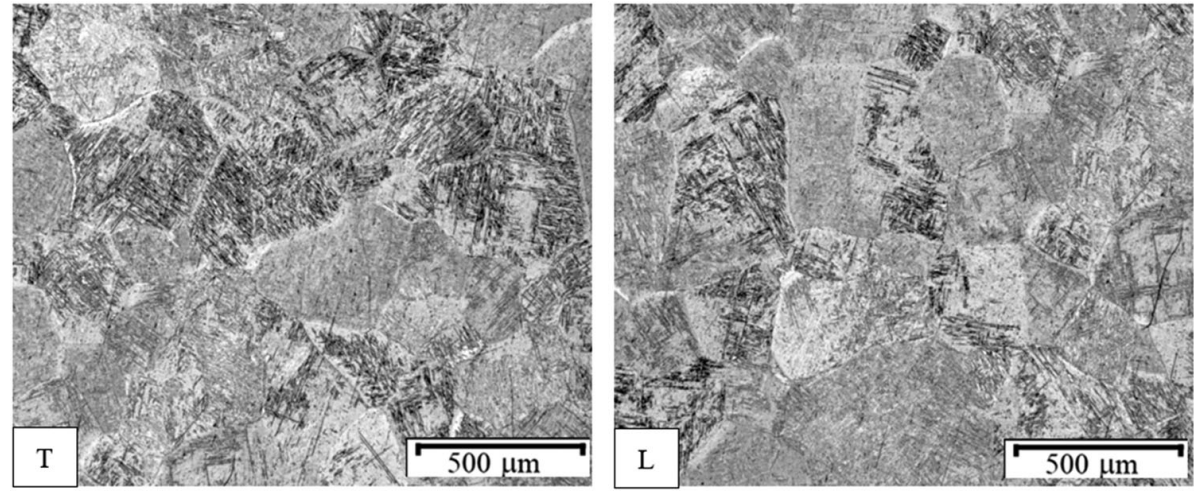

Figure 9. Optical microstructure of additive manufactured $\mathrm{Ti}_{6} \mathrm{Al}_{4} \mathrm{~V}$ transversal $(\mathrm{T})$ and Longitudinal $(\mathrm{L})$ sections.

for both the technologies investigated), while an opposite behavior is observed in the lightest zone (spectrum 3). It is worthwhile to remember that $\mathrm{V}$ is a $\beta$ stabilizer, ${ }^{[33]}$ thus it has to be detected in higher percentages in $\beta$ phase, while in the $\beta$ phase composition of $\mathrm{Al}$, an $\alpha$ stabilizer in the alloy is below the average composition for the alloy. A small amount of iron, that is also a $\beta$ stabilizer, was also detected in the $\beta$ phase. It is expected that Fe will diffuse into the $\beta$ phase during its formation. These observations suggest that the $\alpha+\beta$ structures are formed by diffusion-controlled transformation in which $\mathrm{V}$ diffuses to $\beta$ phase while $\mathrm{Al}$ diffuses to $\alpha$ phase. ${ }^{[3]}$

The differences observed in the microstructure are mainly related to the dissimilarities in the production process which influences the phases shape, dimension, and distribution. These differences are well noted and are mainly related to the importance of the initial microstructure determined by the process itself, as highlighted by Vrancken et al. ${ }^{[21]}$ Due to the very fine martensite, typical of the as-built $\mathrm{SLM} \mathrm{Ti}_{6} \mathrm{Al}_{4} \mathrm{~V}$ samples, the kinetics are completely different as compared with the treatment of equiaxed or heavily deformed microstructures, typical of traditional produced titanium alloys. Consequently, the application of standard heat treatments shows that these treatments do not lead to the usual or expected results and specific parameters have to be applied at additive manufactured parts; their effect differs greatly from one set of parameters to another. ${ }^{[21]}$ Also, Zhou et al. ${ }^{[34]}$ found a very different microstructure for a Ti alloy processed by SLM or hot forging. 


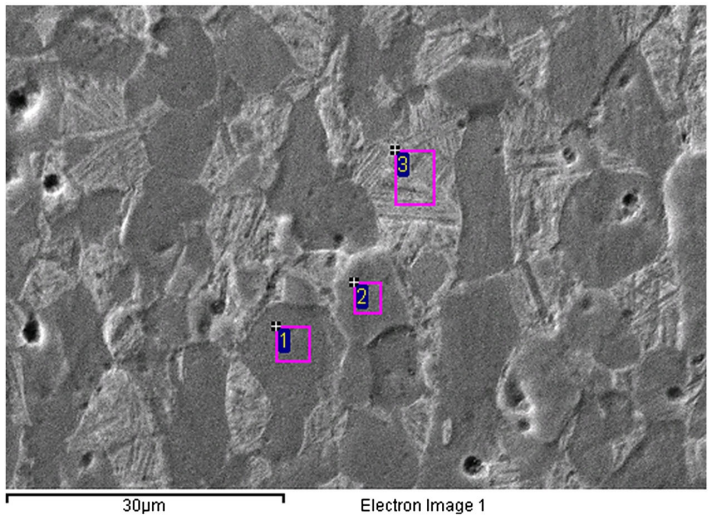

\begin{tabular}{l|lllll}
\hline Spectrum & Al & Ti & V & Fe & Total \\
1 & & & & & \\
2 & 6.91 & 90.96 & 2.13 & & 100.00 \\
3 & 6.79 & 90.94 & 2.27 & & 100.00 \\
& 5.52 & 88.34 & 5.88 & 0.27 & 100.00 \\
\hline
\end{tabular}

Figure 10. SEM micrograph and results of EDS analysis (wt\%) of a representative forged Ti6Al4V conrod section.

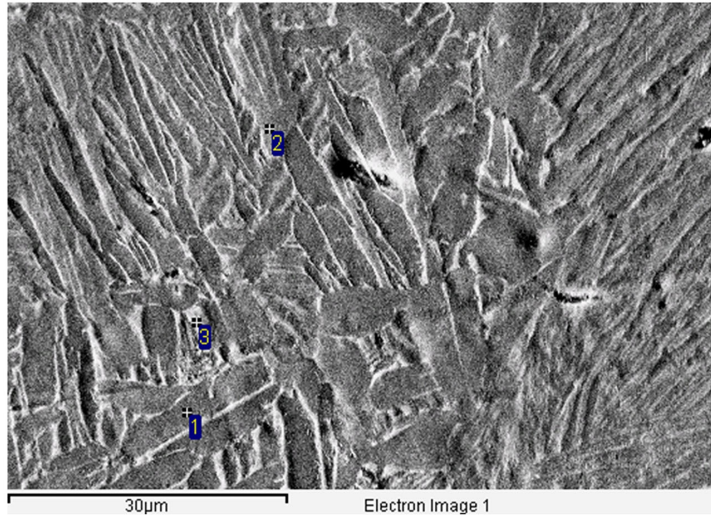

\begin{tabular}{l|lllll}
\hline Spectrum & Al & Ti & V & Fe & Total \\
& & & & & \\
1 & 6.38 & 91.60 & 2.02 & & 100.00 \\
2 & 6.59 & 90.98 & 2.43 & & 100.00 \\
3 & 5.31 & 86.37 & 6.79 & 1.53 & 100.00 \\
\hline
\end{tabular}

Figure 11. SEM micrograph and results of EDS analysis (wt\%) of a representative additive manufactured Ti6Al4V conrod section.

During the current work, the subsequent heat treatments were finalized at reducing anisotropy and residual stresses, typical of both the processes, and avoid the presence of a fully martensitic $\alpha^{\prime}$ microstructure due to its transformation in $\alpha+\beta$ phases. The two processes present different microstructure, as expected in relation with process dissimilarities, but the aforementioned features were achieved for both CM and SLM samples. It is important to remember that these features were achieved due to the detailed preliminary researches on heat treatments ${ }^{[25]}$ that guaranteed the achievement of the proper microstructure on the SLM conrod. In addition, both the microstructures are expected to give good mechanical properties.

It is worthwhile to note that different samples were taken from various areas of the parts, both for SLM and forged conrod, and the results were always aligned. No defects were observed in various samples. As it can be seen from the lower magnifications, both the macrostructures present equiassic and isotropic behavior due to the heat treatment transformation.

\subsection{Tensile Test and Hardness}

In Figure 12a, stress-strain curve for the forged and SLM condition was selected and reported for comparison purposes. The tensile curves were very similar to each other both for SLM

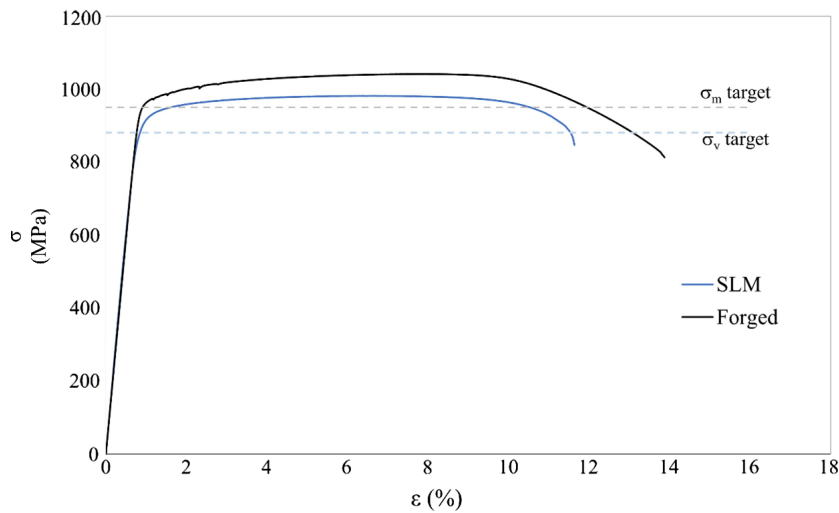

Figure 12. Tensile curves for forged (black) and SLM samples (blue).

and forged samples; thus, the one reported is representative of the general behavior analyzed. Target values of yield strength and stress at break are also included in the graph. Table 1 shows the corresponding values. As it can be seen, similar mechanical properties can be observed for forged and SLM samples, with values slightly higher in the former case. 
Table 1. Mechanical properties measured on forged and SLM samples and target values.

\begin{tabular}{lccc}
\hline & $\sigma_{\mathrm{y}}[\mathrm{MPa}]$ & $\sigma_{\mathrm{m}}[\mathrm{MPa}]$ & $A[\%]$ \\
\hline Forged & $956 \pm 6$ & $1034 \pm 5$ & $13 \pm 0.7$ \\
SLM & $900 \pm 7$ & $974 \pm 11$ & $11 \pm 0.3$ \\
Target & 880 & 950 & 11 \\
\hline
\end{tabular}

The strength of forged samples and the elongation percentage are only $50 \mathrm{MPa}$ and $2 \%$ higher than that of SLM one. This is a good achievement because a good balance between mechanical resistance and ductility was reached due to the specific heat treatment selected for SLM part. Indeed, typically SLM in the as-built condition presents a high strength with a low elongation percentage, as a result of the specific microstructure ( $\alpha^{\prime}$ martensite). ${ }^{[15]}$ This was the same starting condition for the current research (see Cecchel et al.:[25] as-built $\sigma_{\mathrm{y}}=1062 \pm 45 \mathrm{MPa}$; $\sigma_{\mathrm{m}}=1228 \pm 6 \mathrm{MPa} ; A \%=4.5 \pm 1.1 \%$ ). It is also worthwhile to remember that the mechanical properties of SLM differ greatly after the various heat treatments. In general, the yield stress and stress at brake decrease after heat treatment due to the coarsening of the microstructure compared with the original fine $\alpha^{\prime}$ martensite. The difficulty in the dimensioning of the heat treatment parameters stands in finding the right balance between strength and ductility, which was confirmed by the present results. On the contrary, strength of CM is known to not change significantly after the different heat treatments. This is due to the competitive growth of both $\alpha$ the and $\beta$ grains at high temperature that limits the grow of both phases and leads to similar grain sizes after each treatment. ${ }^{[21]}$

It is worthwhile to note that both properties are aligned with the design targets. Indeed, the equiassic and isotropic macrostructure of SLM, composed of a mixture of thin $\alpha$ lamellae and $\beta$ phase, guarantees the proper match of mechanical strength and ductility. This confirms that the heat treatment, selected after preliminary investigations, ${ }^{[25]}$ guaranteed the achievement of the proper microstructure on the SLM conrod to respect the mechanical requirements during its operation. The positive comparison with the tensile properties of the forged samples confirmed these conclusions, proving that the SLM microstructure induced by the heat treatment was proper for the application.

Figure 13 and 14 show the microhardness profile for SLM and forged samples, respectively; the sections analyzed are named as shown in Figure 3. Different profiles were analyzed for each section, with similar results of the one reported in the current summary. It can be observed that some fluctuations are registered along the profile, probably due to the different phases found in correspondence of the specific and local microhardness indentation. This was observed for both the processes.

Some examples of other researches showing large hardness fluctuations in titanium alloy parts can be found for both selective laser melting technology ${ }^{[35,36]}$ and traditional one. ${ }^{[37]}$ Indeed, the mechanical properties of $\mathrm{Ti}_{6} \mathrm{Al}_{4} \mathrm{~V}$, including microhardness, are largely influenced by its microstructure, including constituent phases, the size of the grain and $\alpha$-phase, the texture of prior $\beta$ grains, ${ }^{[15]}$ and crystal structure and orientation. ${ }^{[38]}$ This last factor that changes from one phase to another plays a fundamental

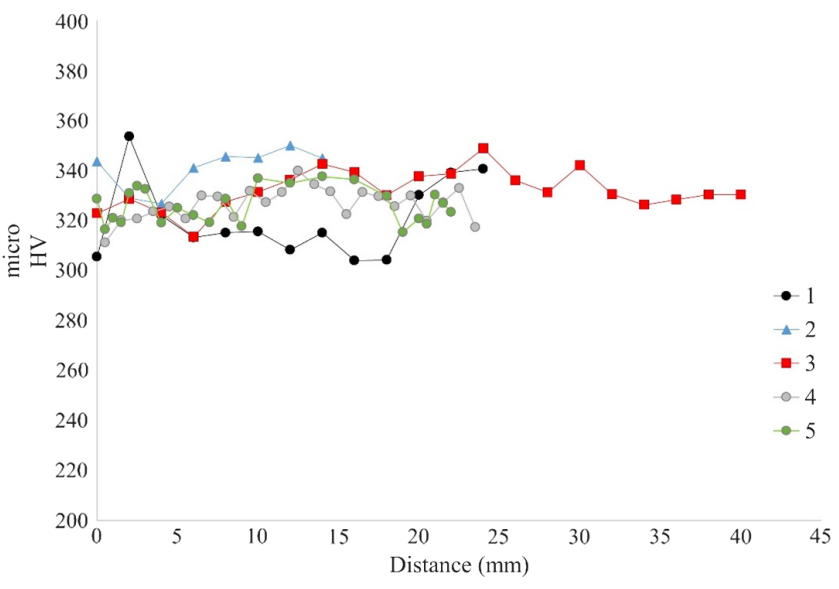

Figure 13. Microhardness profile of forged $\mathrm{Ti}_{6} \mathrm{Al}_{4} \mathrm{~V}$ conrod sections.

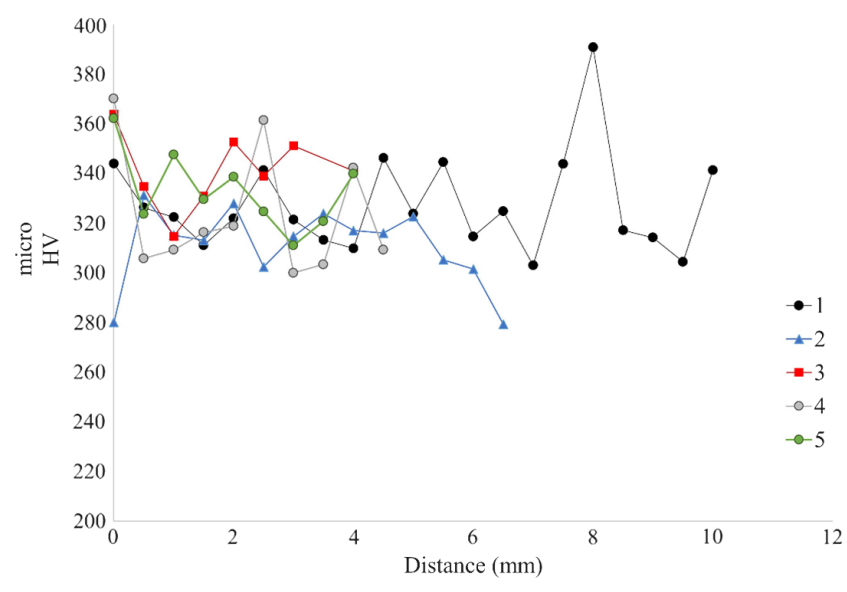

Figure 14. Microhardness profile of additive manufactured $\mathrm{Ti}_{6} \mathrm{Al}_{4} \mathrm{~V}$ conrod sections.

role. ${ }^{[15]}$ Then, hardness fluctuations along the cross section can be ascribed to intrinsic microstructural contributions, namely, the presence of both the soft $\alpha$ and hard $\beta$ phases. ${ }^{[37]}$ These considerations are valid for both CM and SLM processes. In conclusion, hardness fluctuations were observed on both the CM and SLM sections due to intrinsic microstructural contributions.

However, the main result is that the global behavior is very similar between the two processes; indeed, the average hardness measured is $325 \pm 21$ and $328 \pm 10 \mathrm{HV}$ along the forged and SLM samples, respectively.

\section{Conclusion}

The current article started from the topological optimization of a new SLM conrod. Then, microstructures and mechanical resistance of CM and SLM actual conrod parts were analyzed and compared.

The evidence presented in this research can be summarized as follows: 1) A DfAM was developed that can be summarized as an SLM multibranch structure in replacement of the " $\mathrm{H}$ " section of 
the CM component. This allows to put the material only where it is necessary from structural application by reducing the weight. Indeed, the weight reduction achieved was $45 \%$ and $15 \%$ with respect to steel and titanium forging, respectively, and the mechanical resistance was achieved as suggested by the FEA analysis. 2) Other benefits related to the DFAM realized are the manufacturing of the conrod into two separated parts that avoid the difficult machining to separate the cap from the main body, and the integration of conformed cooling channels into the conrod. 3) As expected, different microstructures were observed between CM and SLM samples. The former presented a duplex microstructure composed of equiaxed $\alpha$ grains and lamellar transformed $\alpha+\beta$ grains, while the latter shown equiassic and isotropic macrostructure composed of a mixture of thin $\alpha$ lamellae and $\beta$ phase. It is worthwhile to note that both the macrostructures present equiassic and isotropic behavior due to the heat treatment transformation. No defects were observed for both the technologies. 4) The mechanical properties were verified to be aligned with the design targets. In particular, the most relevant result was that the SLM samples guarantee the proper match of mechanical strength and ductility due to the specific heat treatment selected. The forged samples shown strengths only slightly higher than the SLM ones. This demonstrated the feasibility of the new application and the proper dimensioning of the boundary condition (i.e., alloy, process parameter, heat treatment).

In conclusion, the feasibility of a weight reduction of critical components through the development of a DfAM was demonstrated. The components were successfully produced without defect and the properties were aligned with the expectations. Further development can be done for the future similar application of different automotive parts to reduce the weight of the vehicles and the pollution related to their circulations.

\section{Acknowledgements}

The authors are grateful for the cooperation during the Design for Additive Manufacturing development to Additive Mind department from EOS $\mathrm{GmbH}$.

\section{Conflict of Interest}

The authors declare no conflict of interest.

\section{Data Availability Statement}

Research data are not shared.

\section{Keywords}

additive manufacturing, automotive components, forging, mechanical characterization, microstructures, titanium alloys

Received: January 11, 2021 Revised: March 5, 2021

Published online:
[1] W. E. Frazier, J. Mater. Eng. Perform. 2014, 23, 1917.

[2] S. A. M. Tofail, E. P. Koumoulos, A. Bandyopadhyay, S. Bose, L. O'Donoghue, C. Charitidis, Mater. Today 2018, 21, 22.

[3] E. Chlebus, B. Kuźnicka, T. Kurzynowski, B. Dybała, Mater. Charact. 2011, 62, 488.

[4] M. Simonelli, Y. Y. Tse, C. Tuck, Mater. Sci. Eng. A 2014, 616, 1.

[5] Q. Zhang, Z. Liang, M. Cao, Z. Liu, A. Zhang, B. Lu, Trans. Nonferrous Met. Soc. 2017, 27, 1036.

[6] G. Nicoletto, Int. J. Fatigue 2017, 94, 255.

[7] M. Seabra, J. Azevedo, A. O. Araújo, L. Reis, E. Pinto, N. Alves, R. Santos, J. P. Mortágua, Procedia Struct. Integrity 2016, 1, 289.

[8] S. Cecchel, D. Ferrario, C. Mondini, M. Montani, B. Previtali, J. Mater. Eng. Perform. 2019, 28, 7756.

[9] T. Childerhouse, M. Jackson, Metals 2019, 9, 689.

[10] H. Helms, U. Lambrecht, Int. J. Life Cycle Assess. 2007, 12, 58.

[11] S. Cecchel, G. Cornacchia, M. Gelfi, Mater. Corros. 2019, 70, 70.

[12] H. C. Kim, T. J. Wallington, Environ. Sci. Technol. 2013, 47, 6089.

[13] J. W. Booth, J. Alperovich, P. Chawla, J. Ma, T. N. Reid, K. Ramani, J. Mech. Des. 2017, 139, 100904.

[14] S. L. Campanelli, N. Contuzzi, A. D. Ludovico, F. Caiazzo, F. Cardaropoli, V. Sergi, Materials 2014, 7, 4803.

[15] S. Liu, Y. C. Shin, Mater. Des. 2019, 164, 107552.

[16] J. W. Qiu, Y. Liu, Y. B. Liu, B. Liu, B. Wang, E. Ryba, H. P. Tang, Mater. Des. 2012, 33, 213.

[17] O. Schauerte, Adv. Eng. Mater. 2003, 6, 411.

[18] M. Plancak, D. Vilotic, O. Luzanin, I. Kacmarcik, A. Ivanisevic, D. Movrin, P. Skakun, M. Milutinovic, Int. J. Eng. 2013, 11, 167.

[19] F. H. Froes, H. Friedrich, J. Kiese, D. Bergoint, JOM 2004, $56,40$.

[20] T. Kubota, K. Doi, T. Murakami, Y. Kojima, T. Miura, SAE Int. J. Engines 2016, 9, 483.

[21] B. Vrancken, L. Thijs, J.-P. Kruth, J. Van Humbeeck, J. Alloys Compd. 2012, 541, 177.

[22] L. Thijs, F. Verhaeghe, T. Craeghs, J. Van Humbeeck, J.-P. Kruth, Acta Mater. 2010, 58, 3303.

[23] T. Vilaro, C. Colin, J. D. Bartout, Metall. Mater. Trans. A 2011, 42, 3190.

[24] G. A. Longhitano, M. A. Arenas, A. Conde, M. A. Larosa, A. L. Jardini, C. A. de Carvalho Zavaglia, J. J. Damborene, J. Alloys Compd. 2018, $765,961$.

[25] S. Cecchel, D. Ferrario, G. Cornacchia, M. Gelfi, Adv. Eng. Mater 2020, 22, 2000359.

[26] G. Bocchi, Motori a Quattro Tempi, Hoepli, Milano, IT 1987.

[27] H. Nigus, Mech. Mater. Sci. Eng. J. 2015.

[28] S. Baragetti, E. Scarabotto, P. Bresciani, S. Mor, Progettazione di bielle per motori endotermici (I), http://meccanica-plus.it/ wp-content/uploads/sites/4/2009/06/20040607033_11.pdf (accessed: March 2021).

[29] S. Baragetti, E. Scarabotto, P. Bresciani, S. Mor, Progettazione di bielle per motori endotermici (II), http://meccanica-plus.it/ wp-content/uploads/sites/4/2009/06/20041012007_11.pdf (accessed: March 2021).

[30] Strozzi, Costruzione di Macchine, Pitagora Editrice, Bologna, IT 1998.

[31] ASTM E92-16, Standard Test Methods for Vickers Hardness and Knoop Hardness of Metallic Materials, ASTM International, West Conshohocken, PA 2016.

[32] ISO UNI EN 6892-1:2009, Metallic Materials-Tensile Testing_Part 1: Method of Test at Room Temperature, International Organization for Standardization (ISO), Geneva, SW 2009.

[33] A. Safdar, L.-Y. Wei, A. Snis, Z. Lai, Mater. Charact. 2012, 65, 15.

[34] L. Zhou, T. Yuan, R. Li, J. Tang, M. Wang, F. Mei, Mater. Sci. Eng. A 2018, 725, 329. 
[35] C. Lancea, L. A. Chicos, S. M. Zaharia, M. A. Pop, presented at the 4th Int. Conf. on Computing and Solutions in Manufacturing Engineering 2016, Brasov, RO November 2016.

[36] Y. Torres, P. Sarria, F. J. Gotor, E. Gutiérrez, E. Peon, A. M. Beltrán, J. E. González, Surf. Coat. Tech. 2018, 348, 31.
[37] N. Poondla, T. S. Srivatsan, A. Patnaik, M. Petraroli, J. Alloys Compd. 2009, 486, 162.

[38] L. Y. Qin, J. H. Men, L. S. Zhang, S. Zhao, C. F. Li, G. Yang, W. Wang, Mater. Sci. Eng. A 2019, 759, 404. 